\title{
MEMÓRIAS SENTIMENTAIS DE JOÃO MIRAMAR: CONSTITUIÇÃO DE UMA ORIGEM.
}

\author{
Juarez Poletto \\ Escritor. Mestre em Literatura Brasileira (UFPR). Professor da PUC-PR e do CEFET-PR, \\ unidade de Curitiba.
}

\section{A OBRA}

Veio a público em 1924, composta de 163 fragmentos, a obra Memórias Sentimentais de João Miramar. O livro era esperado com curiosidade pelos amigos, conforme se constata em carta de 1923, de Mário de Andrade a Manuel Bandeira: "Oswald traz um romance (...) segundo me contam interessantíssimo, exageradamente da facção. Morro de curiosidade"1. Os fragmentos e não capítulos constituem-se de variados tipos de discurso, como cartas, citações, impressões, diálogos, descrições, relatos, poemas... E o nexo que une uns aos outros dilui-se facilmente. Isso faz da fábula uma organização pouco precisa, mas que permite vislumbrar um Miramar na infância e adolescência, com amizades escolares e relações familiares; sua precoce viagem à Europa, as experiências várias dessa aventura; e o posterior Miramar, retornado ao Brasil, em suas relações de trabalho, negócios e amizades, em seu crescente desacerto com a esposa paralelo ao envolvimento com a amante (Rolah), em sua derrocada econômica e sentimental e, finalmente, em seu tempo de escritor das memórias.

Trata-se, ainda, de obra rica na enumeração de pessoas reais, da época de 1912 (presente da personagem Miramar), além de representantes da História do Brasil e mundial, quer nas ciências, quer nas artes, e até comparecem personagens de outras obras de ficção. Esse contexto denuncia uma convivência entre o real e o ficcional e, como sugerem Antônio Cândido e Mário da Silva Brito, uma transposição literária das vivências pessoais de Oswald de Andrade ou, em outras palavras, "a experiência vivida sofre elaboração ficcional"2.

\section{AS MEMÓRIAS}

Luís Augusto Fischer afirma que há uma tradição de produção de obras de memórias ficcionais no Brasil, ou melhor, que os principais autores da literatura brasileira enveredaram para esse caminho, e cita Machado de Assis, Clarice Lispector, Graciliano Ramos, Guimarães Rosa, para ficar apenas com os mais reconhecidos. O crítico vai em busca de explicações para esse fato e, no percurso, depara-se com o quase lugar-comum "brasileiro não tem memória", é então que dá a primeira justificativa para a tão intensa produção de memórias em nossa literatura: 
Talvez precisamente porsaberem que não temos memória, nossos melhores romancistas resolveram então criar a memória. Só que o fizeram com uma pequena intervenção, um pequeno desvio: para dizer as verdades imensas que uma memória pode dizer, eles escreveram ficção, isto é, mentiram - o que talvez seja, em nosso país, a melhor maneira de dizer exatamente a verdade.

Seria esse o objetivo de Oswald em suas Memórias Sentimentais? A resposta a essa questão virá mais adiante.

Para Fischer, os enredos das obras que menciona funcionam "a partir de uma indagação pela origem"3, isto é, querem constituir um passado, criar pela ficção uma memória. Mas essa constatação ou suposição ainda não satisfaz e o crítico então afirma:

Quem confessa se examina e se torna, por isso, digno de ultrapassar as condições em que se encontra. Então, a primeira explicação está aqui: a voz do romance memorialístico brasileiro postula um eu enunciador que merece ser ouvido. ${ }^{4}$

Portanto não se trata apenas de identificar uma origem, mas estabelecer quem enuncia e de que lugar e com que sabedoria o faz, ou o que tem para dizer. $O$ ato de enunciar implica um segundo elemento que é o que de fato dará ao enunciado a consistência significativa: o leitor. $\mathrm{E}$ Fischer conclui que o percurso dos escritores assim se fez porque "não havia nem um eu digno de falar e de ser ouvido, nem um tu disponível para a audição" , daí, cada qual a seu modo e tempo criou esse espaço histórico que posiciona o que fala e pressupõe o que lê.

Cabem, pois, agora as questões: Memórias Sentimentais de João Miramar faz parte desse conjunto de obras memorialístico-ficcionais? Também nela há a busca por uma origem? Propõe a constituição de um eu emissor e de um tu leitor?

\section{RESPOSTAS}

As Memórias Sentimentais são um livro de memórias desde o título, mas já nele há, no termo sentimentais, a orientação para a ficcionalidade. Não se trata de uma história de amores de Miramar. Amores há; não constituem, entretanto, o veio central da obra. João Miramar não tem registro de nascimento, a não ser que, por se configurar em tinta e papel, isso lhe servisse de certidão de nascimento e lhe desse existência carnal. Talvez se quisesse considerar 
Miramar um símbolo do próprio autor. Mesmo que se pudesse ter isso como uma verdade em alguns momentos do relato, ainda assim seria somente símbolo, nunca o próprio Oswald.

Ainda que o autor ponha na boca da personagem palavras que gostaria de dizer, quem as diz é a personagem e, portanto, são dela as afirmações. Não há como negar a condição ficcional de Memórias Sentimentais de João Miramar, embora o título sugira um equilíbrio: se em Memórias de João e tem uma proposta de verdade, até pela simplicidade dos termos, em Sentimentais Miramar há a proposição para o devaneio, uma fuga pela não ação. São, portanto, memórias, já que Miramar conta sua história, mas de teor ficcional, uma vez que são fruto da criação de um autor e não um retrato de fatos acontecidos.

Miramar conheceu o pai, mas este morre logo no terceiro fragmento de suas lembranças e permanece esquecido no decorrer de todo o restante do texto. Miramar, um quase desfiliado, não tenta reencontrar uma origem perdida num passado rural e tampouco procura um avô ativo que Ihe sirva de lembrança e lamentação, antes escreve sua trajetória para revelar o rompimento dos laços de origem e não para resgatá-los. Na ausência do pai, sobra-Ihe a mãe, que o chamava para o oratório e a reza convencional, mas Miramar tinha outra vocação: desarticular o estabelecido, como o fez na oração no fragmento 1 :

- Senhor convosco, bendita sois entre as mulheres, as mulheres não têm pernas, são como o manequim de mamãe até embaixo. Para que pernas nas mulheres, amém.

A partir daí já é possível perceber a forma de seu relato de memórias pouco convencional, dispensando os capítulos e substituindo-os pelos fragmentos, com desarticulação do discurso lógico tradicional e instituição de uma ordem da memória que mistura a realidade exterior com o pensamento da personagem, numa simbiose que gera originais metáforas, como no Fragmento 23 QUIROMANCIA:

O Bandeira barítono lia Belmiro Braga e baldava esperanças de entrar para a diplomacia como diplomata. Fazia-se vaticínios perante o pai de calva gramática. *

E mostrava-nos versos dizendo-se partidário da poesia vagabunda mas cheia de alma. Tinha ido passar uma semana gigolete na pensão da Georgina em Santos.

Deixávamo-lo pela noite de desoras e partíamos cear em Nápoles com pizzas escarradas de tomates* e queijo e um vinho recém vindo pelo noturno Caserta. Abria guignol de sonho realejo rítmico rebentador de valsas ao ar estrelado.

Depois, de cima, pensão de artistas, caíam pingos profundos de Chopin na comida. (* Grifo nosso)

Há também nesse discurso interrompido, realizado em pílulas ou porções, implicações outras, que podem remeter desde a uma personalidade fragmentada até a uma consciente 
atitude de denúncia do discurso tradicional. Quanto à primeira opção, abro mão de uma leitura de linha psicológica. Quanto à segunda, aí está o princípio da ruptura, que vai constituir o discurso adotado por Miramar ao escrever suas memórias.

De que forma o discurso se faz o veículo da ruptura? Que ruptura ou contra que rompe?

O rompimento se faz ao convencional, ao estabelecido do comportamento social literário, no que o texto de Miramar combina com os postulados do momento histórico e, portanto, é porta-voz de Oswald de Andrade, quando no fragmento 42. SORRENTO ironiza: “(...) E uma mulher de amarelo informava a um esportivo em camisa que o casamento é um contrato indissolúvel". As convenções, não só o casamento, são objeto da crítica, que toma como ponto de partida o discurso. Oswald, no momento da criação de Miramar, já não vivia mais seu primeiro casamento ou relacionamento amoroso. A vida real nega, pois, a indissolubilidade das relações. A própria personagem desfaz seu casamento. A desestruturação do estabelecido está bem posta no discurso fragmentado da obra. É através do pensamento estilhaçado que se revela o mundo fragmentado ou atitudes novas ao novo momento histórico. A sociedade é mais caótica, o progresso a revoluciona a cada instante. Não cabem mais discursos como o de Mandarim Pedroso, no fragmento 160, quando discorre sobre o comportamento impoluto dos jovens no Clube Recreio Pingue-Pongue, por ocasião de uma dança de salão em que faltou luz. Esse discurso, que destaca Rui Barbosa e critica os versos futuristas, posto na situação em que foi, sugere exatamente o contrário.

(...)Aqui não se lêem romances de baixa palude literária nem versos futuristas! Só se lê Rui Barbosa. Não! Aqui formamos dignos filhos e filhas do grande ser que Bilac chamou na sua frase cinzelada e lapidar 'Astuta e forte, a grande mãe das raças, Eva!' (...) Visto isso, só tenho a inserir na ata do Recreio Pingue-Pongue, um verdadeiro e auspicioso hino congratulatório aos moços que, como verdadeiros São Luíses, se mantiveram em hora tão perigosa na postura que os levará mais tarde como maridos aos fulgurantes páramos da ventura conjugal!

O comportamento cordato e cordeiro dos jovens os faz parecerem marionetes. Isso tudo ocorre ante um Miramar separado da esposa e vindo de uma relação rompida com a amante. É n o mínimo irônico. O mesmo discurso de Mandarim critica o "feminismo contemporâneo" contrapondo-o à enaltecida atitude imóvel das garotas na escuridão do salão. Esse discurso desmorona por si só: o feminismo acaba exaltado pela mobilidade e ação que o caracteriza, em oposição à imobilidade das garotas. Feminismo é, pois, mobilidade, o que confere à mulher participação - proposta modernista. Oswald escreve pelo avesso, e pelo avesso quer ser entendido. Todo discurso retórico em Miramar é a própria ironia do retórico. João Miramar propõe uma nova palavra, ou uma nova articulação do que é necessário dizer. O clube Recreio Pingue-Pongue é um centro de manutenção da situação social e o discurso aí proferido é prova disso, portanto significa o oposto do que Oswald propõe em sua inovadora obra. 
Cabe muito bem o posicionamento crítico de Kenneth D. Jackson a propósito das intenções de Oswald de Andrade e suas Memórias Sentimentais:

A inovação de Oswald representa uma rejeição, não apenas a estilos artísticos precedentes, mas também ao contexto social, cuja expressão teve ligação estreita com aqueles estilos. Nesse contexto, o estilo vanguardista de Miramar representa mais do que a revolta modernista contra o estilo parnasiano $e$ as grandes personalidades literárias e retóricas que dominavam a literatura brasileira. (...) As críticas de João Miramar nas memórias representam a crítica e a rejeição de Oswald de Andrade ao seu próprio passado. 6

Jackson confirma que a obra de Oswald rejeita os padrões tanto sociais como estéticos existentes no seu tempo e o crítico vai mais além, propõe uma rejeição do autor ao próprio passado, portanto um questionamento à origem. Reservamos essa análise para mais adiante, por ora permaneçamos no discurso.

São claras ainda as diferenças entre o que é texto de Miramar e o que são os discursos dos outros inseridos nas Memórias. As cartas de Célia, Nair ou mesmo de Minão da Silva são convencionais no trato da linguagem, no máximo revelam a instrução de quem as emite. Os comentários, falas ou discursos de Dr. Pilatos, Dr. Mandarim, Sr. Fíleas ou Machado Penumbra são altissonantes, pomposos e vazios. Os primeiros representam a família e seus negócios, com quem Miramar rompe ao separar-se da mulher. Os outros são o mundo e suas convenções de clubes, homenagens e aparências, que defendem a manutenção do comportamento e os postulados sociais estabelecidos. Miramar se afasta da família ao preferir a amante (a quem também perde). Quanto aos outros, mostra seus discursos beletristas, como o faz bem nos fragmentos 155. ORDEM E PROGRESSO

Porque nós, meus colegas, meus amigos, neste vale de emoções, de apogeus de quedas de Ícaros, vivemos apenas o romance da eterna pesquisa, da eterna procura, da eterna recherche, da eterna mágoa da miragem! (...)

ou no 160. DISCURSO ANÁLOGO AO APAGAMENTO DA LUZ DURANTE O FOXTROT PELO DR. MANDARIM PEDROSO 
Nele, o espírito hospitaleiro é uma prerrogativa ao lado do catecismo moral da juventude! E é devido a isso que o Recreio Pingue-pongue se tornou célere a mais progressista artéria de nossa vida social, com floridas ramificações pela política e pela literatura! Nele esplendei vós, ó inefáveis portadoras das graças venusinas, aolado dos jovens pegureiros da Pátria!

Mostra esses discursos para dizer que tem proposta diversa. A referida oratória com termos grandiloqüentes, que mais enfeitam do que dizem, traduz uma sociedade e vida de aparências, adequada a um momento histórico passado. Miramar divorciou-se do passado, Célia morreu, os negócios não deram certo, a amante foi-se... É tempo de nova consciência. É preciso pôr um ponto final nessa história.

Que tipo de consciência há em Miramar? Não se trata de consciência ingênua, já que articula um discurso crítico. Não se trata de um indivíduo conformado, que aceita o mundo como é, pois ele o denuncia. É no último fragmento 163. ENTREVISTA ENTREVISTA que se pode deparar com quem seja de fato Miramar: um homem que adquiriu a consciência irônica. $O$ comentário com o repórter sobre as opiniões que Dr. Mandarim e principalmente Dr. Pilatos emitiram sobre a obra

Disse-me o Dr. Mandarim que os viúvos devem ser circunspectos. Mais, que depois dos 35 anos, mezzo del camin di nostra vita, nossa atividade sentimental não pode ser escandalosa (...) Li as Memórias, antes do embarque, ao Dr. Pilatos. (...) O meu livro lembrou-Ihe Virgílio, apenas um pouco mais nervoso no estilo.

e a própria referência aventada pelo repórter, no mesmo fragmento, de que será acusado pela crítica por não continuar "tão rico monumento da língua e da vida brasílicas" são exemplos claros não só da consciência irônica da personagem, como também da transposição dos postulados oswaldianos na voz de Miramar, opinando sobre a academia ou os mais velhos infensos a mudanças. Nas opiniões de Mandarim e Pilatos, está evidente a atitude falsa das afirmações e o descompasso entre a linguagem dos "críticos" e a do texto de Miramar, pois este constitui seu relato de memórias de uma linguagem nova, e ao inserir as falas acadêmicas de algumas personagens no texto e ridicularizá-las, está criticando o que elas representam e revelando o grau de consciência que tem disso. Trata-se de uma crítica, na linguagem, a uma postura social.

As Memórias Sentimentais de João Miramar realizam também uma crítica sobre a escritura de memórias, pelo modo como estão organizadas (desorganizadas?) em fragmentos. Ou ainda, ao apresentar assim as memórias, o autor está propondo uma leitura crítica da memória individual e nacional incompletas e estilhaçadas e do discurso laudatório que sobre a última está estabelecido. É então que negar-se a continuar as memórias se torna significativo: romper consigo próprio e com o passado histórico. Esse rompimento não é para negar-se mas 
constituir-se, isto é, firmar-se sob o signo do não. É assim que se propõe o Modernismo brasileiro: antipassadista, antiacademicista, e é assim que ele se quer novo e sempre renovador, com direito à contínua pesquisa estética.

Memórias Sentimentais de João Miramar não busca uma origem, sua personagem não quer o passado, assim como Oswald o negou em seus manifestos. Esta obra funda uma origem, é um princípio a partir do qual se pretende um homem novo (não o patriarca) e um modernismo no Brasil. Afinal é o "marco zero", "o primeiro cadinho de nossa prosa renovada”7.

Há também aqui um emissor que se revela. Não se trata mais de alguém que organiza e explica a vida, que estrutura causas e conseqüências, que propõe uma lógica. Agora se trata de um narrador que se dispõe, deliberadamente, a desarticular no discurso a vida. Trata-se de narrativa que não mais representa a vida, não mais é símbolo do que acontece. Trata-se de um relato que se constitui em si, que, segundo Lúcia Helena, produz na linguagem uma realidade literária, numa "concepção alegórica de mimese"8. Miramar parece cada vez menos pessoa e sempre mais personagem criada para um determinado fim: apresentar um outro tipo de discurso literário, um texto novo. E quanto mais personagem parece, mais se aproxima do próprio autor, que parece ter feito de si personagem de si mesmo. O ficcional semelha disfarce. Cabe retomar a frase de Kenneth Jackson: "As críticas de João Miramar nas memórias representam a crítica e a rejeição de Oswald de Andrade as seu próprio passado"9. O crítico é bastante direto: Miramar não é apenas personagem, mas também representa o autor, é seu porta-voz, pois através dele é que se faz a denúncia crítica da realidade de seu tempo, das figuras medíocres que faziam aquele momento histórico. O Fragmento 42 SORRENTO diz:

Um inglês velho dormia de boca aberta como uma boca enegrecida de túnel sob óculos civilizados.

O Vesúvio esperava ordens eruptivas de Thomas Cook \& Son.

O Fragmento 88 JABUTUCABAS ironiza a personagem Dr. Pilatos em sua mediocridade de "oh! Ah!" e recheio retórico em falas de autogabar-se, além de expor Dr. Mandarim e suas titulações ocas:

O Dr. Pilatos ficou fulo porque o Dr. Mandarim Pedroso, tesoureiro pé-pé do Banco Nordeste de Engole-Marmanjos e presidente do Recreio Pingue-Pongue, dissera em palestra referidora de um genro seu a frase: - esses incógnitos...

- Chamar de incógnitos! É um rapaz direito, tem o seu cobrezinho.

E continua para mim com argumentos de paletó puxado durante a pesquisa de pomar:

- Eu já com um almoço por semana e cheguei à posição que cheguei. Sou um autodidata! E já fui citado pelo padre Berlangete da Universidade Católica de Beirute. Escrevi a biografia do 
patriarca Basílio 8 que foi torrado numa igreja por causa de Orígenes. Irei a Ravena estudar de perto o século 5. As academias orientalistas abrir-me-ão as portas, oh! ah!

A denúncia do poder estrangeiro, a crítica às convenções saltam aos olhos, mas não é só: a síntese e a surpresa desses fragmentos remetem ao Manifesto da Poesia Pau-Brasil, embora posterior, que declara a rejeição à mentalidade acadêmica e formal pelo "contrapeso da originalidade nativa", o que faz de Miramar uma obra que antecipa na prática sua posterior defesa no Manifesto.

Jackson insiste:

Pode-se dizer que as Memórias Sentimentais retratam o contexto social brasileiro de um modo caricatural e paródico mais aguçado, porque Oswald estava reagindo contra um estilo e um contexto social do qual participava ${ }^{10}$.

Seguramente as personagens da obra simbolizam figuras do mundo real e são postas em julgamento crítico pelo ridículo das situações em que são retratadas. Já no prefácio da satirizada personagem Machado Penumbra se lê: "é o quadro vivo de nossa máquina social que um novel romancista tenta escalpelar com arrojada segurança dum profissional do subconsciente das camadas humanas". A palavra subconsciente esclarece esse caráter não lógico da organização do discurso na obra e, mais, faz compreender a organização subterrânea do enredo e a crítica quase subliminar ao contexto social. Tudo parece sub, até a personagem submerge e se faz caricatural.

Confirmando os argumentos propostos há a própria interpretação de Oswald de Andrade sobre sua produção e suas idéias:

A minha pena foi sempre dirigida contra os fracos... Olavo Bilac e Coelho Neto no pleno fastígio de sua glória. O próprio Graça Aranha quando quis se apossar do modernismo. Ataquei o verbalismo de Rui, a italianitá e a futilitá de Carlos Gomes... Em pintura, abri o caminho de Tarsila... Fui quem escreveu contra o ambiente oficial e definitivo, o primeiro artigo sobre Mário de Andrade e o primeiro sobre Portinari ${ }^{11}$.

Oswald se revela um crítico de seu tempo. Não poupou as pessoas que representavam o atravanco à modernidade e impulsionou os que se lhe semelhavam inovadores.

Há, entretanto, limites na proposta crítica que Oswald faz a seu tempo. Quanto ao mundo social, as relações de trabalho e produção ficam esquecidas e por isso aquém das expectativas. 
Não há um questionamento mais profundo ao mundo que a obra descortina, aliás, a linguagem, seu ponto inovador mais significativo, está além da realidade que ela abrange. Tornou-se, portanto, pouco acessível ao próprio momento histórico, daí talvez ter sido recebida até com desdém, como se fosse brincadeira irresponsável. A própria personagem-título, pela falta de profundidade psicológica - figura caricatural - revela-se pouco comprometida com o que denuncia, como se fosse quase um ato inconseqüente. A opção por um discurso fragmentado possivelmente dificultou a articulação que pudesse revelar a essência de Miramar, cujo nome sugere a imobilidade, a acomodação. No final, Miramar está com a filha, herdeira da mãe, e se cala, cessa as suas memórias. Por quê? Oswald não teria acertado bem a mão? Ou teria ele optado por dar à personagem exatamente essa medida parcial, essa compreensão também do fragmento e não da totalidade do real? O discurso do texto não é feito em gotas dispersas à toa. Aí estão não só o país cuja estrutura não se apreende bem, como também o indivíduo, cuja existência se desestrutura, e se de alguma maneira esse indivíduo participa, também se cala. Enquanto a realidade se mostra pelo discurso, o mesmo discurso encarrega-se de não expô-la plenamente. É um jogo. O jogo de constituir pelo discurso fragmentário uma sociedade fragmentada como uma origem a partir da qual se faz uma nova História. Oswald é mais que Miramar, mesmo que este se mire naquele. Enquanto Miramar tem uma consciência limitada da realidade: tem um discurso novo mas ainda não uma nova atitude; Oswald cria na obra uma realidade fundadora da nova estética: uma origem. Como tudo o que é muito novo é pouco entendido em seu tempo, Miramar mais causou polêmica que compreensão, mas foi a ponta de lança a abrir caminho para a prosa renovada no Brasil.

Notas:

1- ANDRADE, Mário de. Cartas a Manuel Bandeira. Rio: Simões Editora, 1958, p. 60.

2- BRITO, Mário da S. Ângulos e Horizontes. São Paulo: Martins, 1969.

3- FISCHER, Luís Augusto. Para fazer diferença. Porto Alegre: Artes e Ofícios, 1998, p. 130.

4. Idem, p. 135.

5- Ibidem.

6- JACKSON, Kenneth D. A prosa vanguardista na literatura brasileira: Oswald de Andrade. São Paulo: Perspesctiva, 1978, p. 30.

7- CAMPOS, Haroldo de. Miramar na mira. In: ANDRADE, Oswald. Obras Completas. Rio: Civilização Brasileira, 1971, p. 13.

8- HELENA, Lúcia. Totens e tabus da modernidade brasileira. Rio de Janeiro: Tempo Brasileiro, 1985, p. 90.

9- JACKSON, Kenneth D. A prosa vanguardista na literatura brasileira: Oswald de Andrade. São Paulo: Perspectiva, 1978, p. 30. 
10- Idem, p. 32.

11- ANDRADE, Oswald de. Antes do Marco Zero. In: Obras Completas, v. 5. Rio de Janeiro: Civilização Brasileira, 1971, p. 42.

\section{BIBLIOGRAFIA}

ANDRADE, Mário de. Cartas a Manuel Bandeira. Rio de Janeiro: Simões Editora, 1958.

ANDRADE, Oswald de. Memórias Sentimentais de João Miramar. Rio de Janeiro: Editora Civilização Brasileira, 1973.

ANDRADE, Oswald de. In: Ponta de Lança, Obras Completas 5. Antes do Marco Zero. Rio de Janeiro: Editora Civilização Brasileira, 1973.

BRITO, Mário da S. Ângulos e Horizontes. São Paulo: Martins, 1969.

CAMPOS, Haroldo de. In: ANDRADE, Oswald de. Obras Completas 2. Miramar na Mira. Rio de Janeiro: Editora Civilização Brasileira, 1971.

FISCHER, Luís Augusto. Para fazer a diferença. Porto Alegre: Artes e Ofícios, 1998.

HELENA, Lúcia. Totens e tabus da modernidade brasileira: símbolo e alegoria na obra de Oswald de Andrade. Rio de Janeiro: Tempo Brasileiro, 1985.

JACKSON, Kenneth D. A Prosa Vanguardista na Literatura Brasileira: Oswald de Andrade. São Paulo: Perspectiva S.A., 1978. 